\title{
School Mapping Using Geographic Information System
}

\author{
Ana A*, Indah Khoerunnisa, M Muktiarni, Vina Dwiyanti, Asep Maosul \\ Faculty of Technology and Vocational Education \\ Universitas Pendidikan Indonesia \\ *ana@upi.edu
}

\begin{abstract}
Development of school mapping research in various countries illustrates how to improve the quality of human resources by optimizing mapping research. This article aims to explore the development of school mapping, examine the types of school mapping tools used, and explore the data presented in school mapping. The method used is a systematic literature review. The results showed that several countries had conducted school mapping research are UK, Malta, Spain, Kenya, Ghana, India, China, Malaysia, Myanmar, Chile, Canada, Minnesota, Hawaii, New Zealand, and Australia. School mapping research focuses on three topics, consisting of evaluating school policies, mapping as an infrastructure database, and school information tools. The mapping method used for evaluating school policies is a qualitative method, while as a database using geographic information system. This article provides an overview of school mapping research as a solution to improve the quality of human resources, such as mapping vocational schools with industrial availability, and their suitability for regional potential.
\end{abstract}

Keywords—school mapping, vocational education, geographic information system

\section{INTRODUCTION}

Labor market needs can be satisfied by vocational education [1]. Vocational education intended to improve the quality of human resources [2]. Vocational education equip graduates with special skills [3], needed for national development of respective economies [4], Indonesia included. The strong cooperative relationship between vocational schools and industry is one indicator of the success of vocational education [2,5,6]. This collaboration is carried out to support several vocational programs that are mutually beneficial to industry, such as internships, industrial visits, job training, and other programs [7]. Vocational schools play a critical role by providing competency-based education that links and matches with industry needs, while industry provides vocational guidance and development meant to produce competent industrial workers $[8,9]$. Vocational skills spectrum must be aligned to the needs of the industry [10].

Currently there are 14218 registered Vocational Schools in Indonesia. 3,584 are public vocational schools, and 10,634 are private vocational schools [11]. All the vocational schools are collectively offering 9 expertise areas, made up of 48 programs, and 142 competencies [12]. These areas, programs, and competencies are meant to address the human resources needs of industry and world of business [13]. The relationship between vocational schools and industry is indispensable because the two parties can craft a workable curriculum [14]. Aligning a vocational curriculum to the labor needs of industry and business is mountainous because there are so many stakeholders whose input during the curriculum development process might be contrary to the interests of the labor employers [15]. In order to effectively align the curriculum to the labor needs of industry and business, the purpose should be aligned to assessment instruments, learning objectives should be aligned to the instructional pedagogies, and assessment instruments should also be aligned instructional pedagogies [16]. Skills gap can be eliminated through an intensive curriculum and school mapping. The skills gap can be closed if a vocational curricula is labor market driven [17].

Curriculum mapping is the process of itemizing or sketching a curriculum to identify and deal with academic gaps, excesses, and misalignments. School mapping is defined as the representation of information in a visual or textual form that can connect one information with the other [18]. This form of mapping varies depending on the purpose of development and use. School mapping plays an important role in providing information on the establishment of schools as per their mandate [19]. It is also invaluable when building a school geospatial database that supports infrastructure development, policy analysis, and decision making [20]. School data or information can be updated at any time [21]. One method used for this mapping is the Geographic Information System (GIS).

GIS is a computer-based tool for geographic data analysis and spatial visualization [21]. This tool provides a themeoriented database and information that supports many representations, and information links [22]. The ability to process, analyze, and visualize spatial data [23,24], calculate the distance between zones accurately [25], is the function of GIS as a tool [26]. In relation to school mapping, GIS regulates data and information about the spread of vocational schools. 
This article aims to explore the extent of the development of the current school mapping, to analyze the type of mapping tools that are used as school mapping tools, and to explore the data and information presented in school mapping.

\section{RESEARCH METHOD}

The method used in this article is a systematic literature review. This method was chosen because it can identify, evaluate, and interpret data and research results in accordance with predefined research questions [27], Additionally, systematic literature review can be used to minimize bias, distribute literature search framework, and makes it possible to do a comprehensive analysis [28], Systematic literature review is intended to explore the extent of the development of the current school mapping, to analyze the type of mapping tools that are used as school mapping tools, and to explore the data and information presented in school mapping.

A systematic literature review consists of three stages: literature search and filtering, literature analysis, and writing the results of the analysis in the form of scientific arguments. Literary sources come from several online sources. Some library databases used are Google Scholar, Scopus, and Thomson. The publishers used are direct science, Springer, Taylor and Francis, IOP, DOAJ and nature. The keywords used for literature search are school mapping, industry mapping, school and industry mapping, geographic information systems, curriculum alignment, curriculum relevance, relationships and matches, industrial relations industry, industrial school collaboration, vocational schools, vocational schools and the determination of vocational schools. In addition to keywords, there are specific criteria for filtering literature search, are articles published last five years (2014-2019), a journal, and a research article. Each article is evaluated by researchers to the three main focuses of the discussion are the development of school mapping, mapping tools that are used, and the content of the information presented.

\section{RESULTS AND DISCUSSION}

In the last five years of research mapping is quite a concern in many areas, but more mapping in the context of the environment, compared with the school mapping. Some countries are already conducting research on school mapping to various destinations were China [29], UK [29,30], Malta [31], Chile [32], New Zeland [33], Spain [34], English [35,36], Minnoseta [37], Myanmar [20], India [19], Aurangabad [18], Kenya [38], US [39,40,41], Ghana [42], Malaysia [43,44], Canada [45], Hawai [46], Europe [47,48], and Australia [49].

\section{A. School Mapping as a Tool for Educational Policy Evaluation}

Results literature review show most studies of school mapping focus on three things, are the evaluation of school policy or a broader policy relating to the evaluation system of education, the use of mapping tools as a database infrastructure and facilitate of informing schools to help prospective users make school choices. Some policies that utilize mapping as evaluation tools such as the problem of dropouts in Savelugu district -six communities in the Northern Territory Nanto Ghana [42], Dropout incident mapping analyzed using a case study in 89 children (64 boys and 25 girls, aged 7-16 years) who dropped out. The mapping school addressed that many factors are interrelated to increasing dropout rates, so that the cooperation between the various parties, including teachers, principals, associations of parents-teachers, school management committees and community members are needed to address the factors at risk of premature and increasing the number of dropouts.

Another study discussed the mapping of school environments that have an impact on obesity in students due to uncontrolled physical activity [30], The mapping framework of the school environment includes consisting of the school environment in urban and rural areas, with aspects of assessment covering: physical, economic, political, and sociocultural. The method used to identify this is interview and observation. The school environment with a percentage of more than 60 has been good in managing the school environment so that it supports the learning process of students and does not have an impact on obesity of students.

\section{B. School Mapping as Database Information Infrastructure}

In addition to the recent discussion of school mapping studies relating to school infrastructure, such as mapping studies in India [19], school mapping was used to help assess the condition of educational infrastructure with the help of GIS mapping tools. There were 204 schools in 114 Jasra India Block villages analyzed for infrastructure availability, including location, building, laboratory, electricity, water information, students were male, female students, teachers, academic staff, and the number of vacant positions. In addition to the recent discussion of school mapping studies relating to school infrastructure, such as mapping studies in India [19], school mapping was used to help assess the condition of educational infrastructure with the help of GIS mapping tools. There were 204 schools in 114 India Block villages analyzed for infrastructure availability, including location, building, laboratory, electricity, water information, students were male, female students, teachers, academic staff, and the number of vacant positions. School mapping that aims to determine the condition of infrastructure has also been implemented in Myanmar [20], an Android application is used to detect the condition of school infrastructure. The tools used for mapping are SQLite, B-tree, Oracle, SQL, PostgreSQL, and SQL servers. The school database is stored in SQLite, the index structure is built by combining B-tree files inverted. The school mapping application is developed in the Android version 4. School information can be accessed and updated at any time.

In contrast to school mapping relating to the analysis of school policies and the education system, to determine school infrastructure, the research method used is the development of information systems with the help of tools. Suitable tools are used, namely GIS and databases such as SQLite. This mapping 
can also be used as an information source to consider the selection of schools for users.

\section{School Mapping as Determination Choosing Schools}

School mapping can also be used to assist users in determining schools according to the desired requirements. Mapping schools in Aurangabad [18], education was degraded because of the wrong choice in school. $50 \%$ of parents choose the closest school according to availability. School mapping emerged as an idea to choose the best schools in the area around the community's reach to improve education standards and to make the right choices. Similarly, school mapping as a school information system, the method used is development using GIS tools.

\section{CONCLUSION}

The breadth of the mapping research contecx that does not only focus on one area provides opportunities for developing countries to deal with the supply of quality human resources. Mapping research developed in various fields, one of which was school mapping. School mapping currently focuses on three aspects, namely determining the analysis or evaluation of school policies both related to student activities, environmental conditions, as well as central government policies, can be mapped using concept mapping and strengthened by qualitative methods. In addition, the use of a GIS mapping tool that can be optimized as a tool for collecting spatial databases that serves to provide information to the outside community by optimizing the information system built. This system can be a reference for the community in making decisions, such as choosing a school based on the availability of infrastructure, environmental conditions, teachers, academics, and other things considered to be informed.

\section{REFERENCES}

[1] A.G. Forster and T. Bol, "Vocational Education and Employment Over the Life Course Using A New Measure of Occupational specificity," Soc. Sci. Res., Vol. 70, no. March 2017, pp. 176-197, 2017.

[2] W. Eichhorst, RN Planas, R. Schmidl, and KF Zimmermann, "A Road Map To Vocational Education And Training In Industrialized Countries," ILR Rev., Vol. 68, no. 2, pp. 314-337, 2015.

[3] J. Hartog, PS Raposo, and H. Reis, "Vocational High School Graduate Wage Gap: The Role of Cognitive Skills and Firms," Labor Econ., No. 11549, 2018.

[4] Paryono, "The Importance of TVET and Its Contribution to Sustainable Development" AIP Conf. Proc., Vol. 1887, 2017

[5] I.D.A Nurhaeni, Y. Kurniawan, AW Hashim, and FP Hernawan, "A study of the impact of cooperation between vocational high schools and industries in Malang City," J. Phys. Confere Ser., 2018.

[6] I.D.A Nurhaeni, Y. Kurniawan, AW Hashim, and FP Hernawan, "A Study of the Impact of Cooperation between Vocational High School and Industries in Malang City," J. Phys. Confere Ser., 2018.

[7] NA Yunikawati, PH Prayitno, MP Purboyo, N. Istiqomah, and E. Yunika, "Causes and Solution To Reduce Unemployment Vocational School Graduate in Indonesia," no. November, pp. 24-25, 2017.
[8] Permenperin, "Guidelines for Promotion and Development CompetencyBased Vocational High School who Link and Match with industry." 2017.

[9] AR Bakar and I. Hanafi, "Assessing Employability Skills of TechnicalVocational Students in Malaysia, "J. Soc. Sci., Vol. 3, no. 4, pp. 202 207, 2007.

[10] A. Bakker, A. Bakker and S. Akkerman, "The Learning Potential of Boundary Crossing in The Vocational Curriculum," Handb. Vocat. Educ., No. July, 2017.

[11] K. Directorate of Vocational, CMS Data Book 2017, 2017.

[12] A. Ait Si mhamed, "Shaping the futures of (vocational) education and work: Commitment of VET and VET research," Int. Rev. Educ., Vol. 63, no. 4, pp. 605-607, 2017

[13] S. Arafeh, "Curriculum mapping in higher education: a case study and the proposed content scope and sequence mapping tool," J. Furth. High. Educ., Vol. 40, no. 5, pp. 585-611, 2016

[14] NM Albashiry, JM Voogt, and JM Pieters, "Curriculum Design Practices of a Vocational College in a Developing Context: Challenges and Needs," Community Coll. J. Res. Pract., Vol. 39, no. 12, pp. 1137-1152, 2015 .

[15] LW LW Anderson and Anderson, "Curricular Alignment: A ReExamination," no. September 2013, pp. 37-41, 2010.

[16] SG Archambault and J. Masunaga, "Curriculum Mapping as a Strategic Planning Tool," J. LiBr. Adm., Vol. 55, no. 6, pp. 503-519, 2015

[17] L. Ervin, B. Carter, and P. Robinson, "Curriculum mapping: Not as straightforward as it sounds," J. Vocat. Educ. Train., Vol. 65, no. 3, pp. 309-318, 2013.

[18] Khobragade and K. SP. Kale, "School Mapping System Using GIS for Aurangabad City,"Res. J. Pharm. Biol. Chem. Sci., Vol. 4, no. 10, pp. 17110-17119, 2016

[19] S. Agrawal and RD Gupta, "School Mapping and Geospatial Analysis of The Schools in Jasra Development Block of India," Int. Arch. Photogramm. Remote Sens. Spat. Inf. Sci., Vol. XLI, no. July, pp. 145 $150,2016$.

[20] MM Sein, Maung SZM, MT Khine, Phyo K., T. Aung, and PPP Tun, "School Mapping for Schools of Basic Education in Myanmar," Nature, Vol. 744, pp. 115-122, 2018

[21] S. Liu and X. Zhu, "Designing a structured and interactive learning environment based on GIS for geography secondary education," J. Geog., Vol. 107, no. 1, pp. 12-19, 2008.

[22] Umar Shuaibu, SMJ, and KMS, "Application of Geographic Information System (GIS) in Mapping the Distribution and Management of Schools in Dass Local Government Area of Bauchi State," Proc. Acad. Conf. African Sch. Publ. Res. Int. Chall. Prospect., Vol. 8, no. 5, 2015.

[23] W.A. Marra, L. van de Grint, K. Alberti, and D. Karssenberg, "Using GIS in an Earth Sciences course for quantitative field exploration, the data management and digital mapping," J. geogr. High. Educ., Vol. 41, no. 2, pp. 213-229, 2017.

[24] C.J. Peters, NL Bills, AJ Lembo, JL Wilkins, and GW Fick, "Mapping Potential Foodsheds in New York State: A Spatial Model for Evaluating the Capacity to Localize Food Production," Renew. Agric. Food Syst., Vol. 24, no. 1, pp. 72-84, 2009.

[25] J. Hohn, E. Lehtonen, S. Rasi, and J. Rintala, "A Geographical Information System (GIS) based methodology for determination of potential biomasses and sites for biogas plants in southern Finland," Appl. Energy, Vol. 113, no. 2014, pp. 1-10, 2014.

[26] W. Isma et al."Geographic Information System of West Java Batik: Cultural and Industrial Mapping for Supporting the Development of Curriculum in Vocational High Schools," Journal Eng. Scince Technol., Vol. 13, no. 7, pp. 1979-1991, 2018.

[27] L. García-Borgoñón, M.A. Barcelona, J.A. García-García, M. Alba, and MJ Escalona, "Software process modeling languages: A systematic literature review," Inf. Softw. Technol., Vol. 56, no. 2, pp. 103-116, 2014 
[28] J. Rao and J. Ye, "From a virtuous cycle of rural-urban urban-oriented education to basic education in rural China: An explanation of the failure of China's Rural School Mapping Adjustment policy," Rural J. Stud., Vol. 47, pp. 601-611, 2016.

[29] J. Arnold, S. Bruce-Low, S. Henderson, and J. Davies, "Mapping and evaluation of physical activity interventions for school-aged children, "Public Health, vol. 136, pp. 75-79, 2016.

[30] L. Earl, "Children's food maps: using social mapping to understand school foodscapes" Ethnogr. Educ., Vol. 13, no. 4, pp. 508-528, 2018.

[31] M. Briguglio and A. Debattista, "Mapping the outcomes of a schoolbased cultural program," City, Cult. Soc., Vol. 11, no. August, pp. 3949, 2017.

[32] A. Vásquez, K. Marinkovic, M. Bernales, J. Leon, J. González, and S. Castro, "Children's views on evacuation drills and school preparedness: Mapping unfolding experiences and perspectives," Int. J. Disaster Risk Reduct., Vol. 18, pp. 1-47, 2018.

[33] T. Stewart, J. Schipperijn, B. Snizek, and S. Duncan, "Adolescent school travel: Is online mapping a practical alternative to GPS-assessed Routes travel ?," J. Transp. Heal., Vol. 5, pp. 113-122, 2017.

[34] O. Moliner, A. Sales, and A. Sanahuja, "Social Mapping in the Context of a Community-build Day: Strategy to Strengthen Links with the community in a Small Rural School," Procedia - Soc. Behav. Sci., Vol. 237, no. June 2016, pp. 305-310, 2017.

[35] A. Demetriou, Merrell C., and P. Tymms, "Mapping and predicting literacy and reasoning skills from early to later primary school," Learn. Individ. Differ., Vol. 54, pp. 217-225, 2017.

[36] S.J. Courtney, "Mapping of school types in England," Oxford Rev. Educ., Vol. 41, no. 6, pp. 799-818, 2015.

[37] N. Gislason, "Mapping school design: A qualitative study of the relations among facilities design, curriculum delivery, and school climate," J. Environ. Educ., Vol. 40, no. 4, pp. 17-33, 2009.

[38] G.C. Mulaku and E. Nyadimo, "GIS in Education Planning: The Kenyan School Mapping Project," Surv. Rev., Vol. 43, no. 323, pp. 567-578, 2011.

[39] D. Sohoni and S. Saporito, "Mapping School Segregation: Using GIS to Explore Racial Segregation between Schools and Their Corresponding Attendance Areas," Am. J. Educ., Vol. 115, no. 4, pp. 569-600, 2009.
[40] T.L. Green, "Places of Inequality, Places of Possibility: Mapping 'Opportunity in Geography' Across Urban School-Communities," Urban Rev., Vol. 47, no. 4, pp. 717-741, 2015.

[41] K. Kretchmar, B. Sondel, and JJ Ferrare, "Mapping the terrain: Teach For America, charter school reform, and corporate sponsorship," J. Educ. Policy, Vol. 29, no. 6, pp. 742-759, 2014.

[42] J.G. Ampiah and C. Adu-Yeboah, "Mapping the incidence of school dropouts: A case study of communities in Northern Ghana," Comp. Educ., Vol. 45, no. 2, pp. 219-232, 2009.

[43] HAMA Majid, A. Danis, SKA Sharoni, and M. Khalid, " Whole School Environmental Mapping Framework and Observation 'in Preventing Childhood Obesity, " Procedia - Soc. Behav. Sci., Vol. 201, no. February, pp. 102-109, 2015.

[44] M. A. M. Hayati Adilin, M. Holdsworth, F. McCullough, J.A. Swift, and A.K. Norimah, "Whole School Mapping to Investigate the School Environment's Potential to Promote a Heathy Diet and Physical Activity in Malaysia," Malays. J. Nutr., Vol. 21, no. 1, pp. 1-14, 2015.

[45] J.Y.Y. Kwan, J. Nyhof-Young, P. Catton, and ME Giuliani, "Mapping the future: Towards oncology curriculum reform in undergraduate medical education at a canadian medical school," Int. J. Radiat. Oncol. Biol. Phys., Vol. 91, no. 3, pp. 669-677, 2015.

[46] L.J. Hsu, MY Pacheco, C. Crabtree, and JE Maddock, "Using Concept Mapping in the Development of a School of Public Health," Hawaii. J. Med. public Health, Vol. 74, no. 7, pp. 224-229, 2015.

[47] Q. Xu, HR Jäger, M. Husain, G. Rees, and P. Nachev, "The Rise of a New Associationist School for lesion-Symptom Mapping," J. Neurol., Vol. 141, no. 1, pp. 48-54, 2018.

[48] P. Reiska, K. Soika, and AJ Cañas, "Using concept mapping to measure changes in interdisciplinary learning during high school," Knowl. Manag. E-Learning, Vol. 10, no. 1, pp. 1-24, 2018.

[49] S. Osborne, LI Rigney, T. Benveniste, J. Guenther, and S. Disbray, "Mapping Boarding School Opportunities for Aboriginal Students from the Central Land Council Region of Northern Territory, "Aust. J. Indig. $\begin{array}{llll}\text { Educ., } & \text { Pp. } & 1-17, & \end{array}$ 